\title{
Referrals to a regional neonatal intensive care unit
}

\author{
H P ROPER, M L CHISWICK, AND D G SIMS \\ North Western Regional Perinatal Centre, St Mary's Hospital, Manchester
}

SUMMARY Over a three year period 444 requests for the neonatal transfer of babies with acute medical problems were received at this regional neonatal medical unit. Despite an increase in available resources in the North Western Health Region the provision of intensive care remained inadequate with $38 \%$ of requests declined, and babies had to be referred elsewhere including to neighbouring health regions. The survival of those babies who had to remain at the hospital of birth $(49 \%)$ was significantly lower than for those transferred to the regional centre $(71 \%)$. Those babies declined admission had significantly lower gestational ages and birth weights than those accepted. For those babies with respiratory failure and birth weights of less than $1500 \mathrm{~g}$ within these two groups, however, there were no significant differences in birth weight, gestational age, or gender yet survival was significantly better for those transferred. Babies from multiple pregnancies caused particular problems if neonatal transfer was required.

We have previously drawn attention to the outcome for babies in the North Western Region who were declined admission to the regional neonatal intensive care unit at this hospital because the demand outstripped availability of accommodation. ${ }^{1}$ During a 12 month period in $1979-80$ we declined $65(38 \%)$ of 170 requests for neonatal transfer of babies with acute medical problems. The survival rate of those babies with respiratory failure who were declined admission and who had to remain in their local unit was significantly worse than those who were transferred.

Since that report the number of intensive care cots on our unit has increased from 10 to 15 , and a subregional unit of six neonatal intensive care cots opened at Hope Hospital, Salford. Furthermore, paediatricians at certain district general hospitals in the region have been undertaking an increasing amount of neonatal intensive care. ${ }^{2}$

We now report the experiences of the regional neonatal intensive care unit over a consecutive three year period since these changes came about.

\section{Patients and methods}

From 1979 one of us (DGS) has kept a record of requests for neonatal medical transfer. From 1 January 1983 to 31 December 1985 , each time a request was received by the neonatal registrar or consultant to transfer a baby to the regional neonatal intensive care unit at this hospital ('the regional centre') a form was completed giving details including the name of the referring hospital and paediatriian; date and time of the request; the name, sex, birth weight, gestational age, and date and time of birth of the baby. The reasons for requesting transfer were noted.

The following definitions were used: (a) impending or actual respiratory failure: deteriorating respiratory distress or respiratory distress with superimposed apnoeic attacks, or recurrent apnoeic attacks alone, or ventilatory failure from birth, or prolonged ventilator dependence; (b) deteriorating respiratory distress: tachypnoea, thoracic cage retracion, or grunting worsening over the course of four hours, or accompanied by a progressive fall in arterial $\mathrm{pO}_{2}$, blood $\mathrm{pH}$, or a rise in arterial $\mathrm{pCO}_{2}$; (c) respiratory distress with superimposed apnoeic attacks: tachypnoea, thoracic cage retraction or grunting punctuated by episodes of apnoea; (d) recurrent apnoeic attacks: repeated episodes of apnoea without respiratory distress; (e) ventilatory failure from birth: a persisting need for positive pressure ventilation from birth because of inability to maintain spontaneous breathing; and (f) prolonged ventilator dependence: difficulty in weaning a baby from a mechanical ventilator as judged by the referring paediatrician.

If transfer was declined by the staff of the regional centre the reason was recorded according to the following criteria: (a) insufficient intensive care accommodation taking into account the predicted 
needs of high risk inborn babies during the forthcoming 24 hours; (b) insufficient essential items of equipment; (c) shortage of trained neonatal nurses; (d) medical staff unavailable to transfer the baby; (e) transfer not thought to be in the baby's best interests on medical grounds. Decisions to decline requests for transfer were made jointly between the senior neonatal sister on duty and the neonatal registrar or consultant, except for refusal on medical grounds, which was always discussed with the consultant.

At the end of each successive year of the study referring units were asked about the outcome for those babies declined transfer to the regional centre, whether they remained at their local hospital or were accepted elsewhere, and whether they survied or died.

The significance of data was analysed by $\chi^{2}$ tests for comparison of proportions, and by Student's $t$ test for comparison of means. Where appropriate $95 \%$ confidence intervals were calculated.

\section{Results}

During the three year period 444 requests for neonatal transfer were received from 23 maternity hospitals including six that were outside the North Western Region, and from one domiciliary birth. The mean (SD) of gestational age and birth weight of babies for whom transfer was requested was 30.5 (4-1) weeks (range 23-42 weeks) and $1566(790) \mathrm{g}$ (range 460-4440 g). Impending or actual respiratory failure was the reason for requesting transfer in 418 $(94 \%)$ of babies. Other reasons were prematurity alone $(n=9)$, perinatal asphyxia alone $(n=3)$, congenital malformation $(n=6)$, need for parenteral nutrition $(n=4)$, renal failure $(n=2)$, drug overdose $(n=1)$, and local intensive care facilities already full $(\mathrm{n}=1)$.

Requests for transfer were declined in 170 (38\%) of the 444 cases. The annual number of requests and the numbers declined are shown in table 1. Among individual hospitals that used the referral service at least four times during the study the frequency which their total number of requests for transfer was refused ranged from $17 \%$ to $57 \%$.

Among the 170 babies who were declined admission a combination of criteria was responsible in 146 $(86 \%)$ in as much as the unit was working to

Table 1 Requests for transfer 1983-5

\begin{tabular}{lrrrl}
\hline & 1983 & 1984 & 1985 & Total \\
\hline No of requests & 121 & 158 & 165 & 444 \\
No (\%) accepted & $69(57)$ & $94(59)$ & $111(67)$ & $274(62)$ \\
No (\%) declined & $52(43)$ & $64(41)$ & $54(33)$ & $170(38)$ \\
\hline
\end{tabular}

capacity in relation to the available intensive care cots, the number of trained nursing staff, and the availability of essential equipment such as mechanical ventilators and monitoring equipment. Ten babies $(6 \%)$ were declined admission solely because of a shortage of trained nursing staff, and seven $(4 \%)$ were declined because medical staff were unavailable to transfer the baby because another transfer was already in progress. Seven babies $(4 \%)$ were declined transfer on medical grounds. Four of them had respiratory distress but were stable and were judged not to need intensive care at the time. All of them remained at their local hospital and three survived. The baby who died suffered an intracranial haemorrhage and had been born to a mother with idiopathic thrombocytopenic purpura. One term baby had craniosynostosis and choanal atresia and was referred to a more appropriate specialist at another hospital where he later died. Two babies were felt to be too preterm to benefit from transfer; one remained in the local hospital and died, the other was transferred elsewhere and also died.

Among the 393 babies in whom transfer was requested within 48 hours of birth $156(40 \%)$ were declined admission. In contrast, 14 out of 51 babies $(28 \%)$ were declined admission when transfer was requested after 48 hours of age. Among accepted babies, $19(7 \%)$ were more than 7 days old compared with three $(2 \%)$ among those declined $(p<0.05)$. The 274 accepted requests included one baby who was transferred twice, seven who were so ill that they died before they could be transferred, and three who were not transferred because their condition suddenly improved immediately after the request for transfer was made. Therefore 263 were finally admitted to the regional centre.

Of the 170 babies who were declined transfer 135 $(79 \%)$ were subsequently accepted at other units within the region, or at units outside the region $(n=25)$. Three of these babies died before transfer could be effected. The other 35 babies for whom intensive care was unsuccessfully sought remained in their hospital of birth (table 2).

The reasons for requesting referral for babies accepted at the regional centre and for those declined were similar (table 3 ). The birth weight, gestational age, and gender of babies who were transferred to the regional centre, transferred elsewhere, or who remained in their hospital of birth are shown in table 4 . The mean birth weight and gestational age of babies who remained in their hospital of birth were significantly lower compared with those who were transferred to the regional centre.

The survival rate of babies until discharge home 
Table 2 Final result of referral request

\begin{tabular}{|c|c|c|c|c|}
\hline & 1983 & 1984 & 1985 & Total \\
\hline No of babies accepted and transferred & 68 & $90^{*}$ & 105 & 263 \\
\hline No of babies accepted but not transferred & 1 & 3 & 6 & 10 \\
\hline $\begin{array}{l}\text { No of babies delined but accepted } \\
\text { elsewhere and transferred }\end{array}$ & 40) & 49 & 43 & 132 \\
\hline $\begin{array}{l}\text { No of babies declined, accepted elsewhere } \\
\text { but not transferred }\end{array}$ & 2 & 1 & 0 & 3 \\
\hline No of babies declined and stayed local & 10 & 14 & 11 & 35 \\
\hline
\end{tabular}

*One baby transferred twice.

Table 3 Reasons for referral requests

\begin{tabular}{|c|c|c|c|c|}
\hline \multirow[b]{2}{*}{ Respiratory failure: } & \multicolumn{2}{|c|}{$\begin{array}{l}\text { No }(\%) \text { of babies accepted } \\
(n=274)\end{array}$} & \multicolumn{2}{|c|}{$\begin{array}{l}\text { No }(\%) \text { of babies declined } \\
(n=170)\end{array}$} \\
\hline & & \multirow{6}{*}{$(93 \cdot 5)$} & & \multirow{6}{*}{$(95 \cdot 3)$} \\
\hline Deteriorating respiratory distress & $135(49 \cdot 3)$ & & $94(55 \cdot 3)$ & \\
\hline Apnoea & $17(6 \cdot 2)$ & & $9(5 \cdot 3)$ & \\
\hline Respiratory distress and apnoea & $34(12 \cdot 4)$ & & $19(11 \cdot 2)$ & \\
\hline Ventilatory failure from birth & $66(24 \cdot 1)$ & & $40(23 \cdot 5)$ & \\
\hline Prolonged ventilator dependence & $4(1 \cdot 5)$ & & 0 & \\
\hline Prematurity alone & $7 \quad(2 \cdot 6)$ & & $2(1 \cdot 2)$ & \\
\hline Asphyxia alone & $1 \quad(0 \cdot 4)$ & & $2 \quad(1 \cdot 2)$ & \\
\hline Congenital malformation & $4 \quad(1 \cdot 5)$ & & $2(1 \cdot 2)$ & \\
\hline Need for parenteral nutrition or long line & $3(1 \cdot 1)$ & & $1 \quad(0 \cdot 6)$ & \\
\hline Renal failure & $2(0 \cdot 7)$ & & & \\
\hline Drug overdose & $1 \quad(0 \cdot 4)$ & & & \\
\hline Local intensive care facilities full & & & $1 \quad(0 \cdot 6)$ & \\
\hline
\end{tabular}

Table 4 Birth weight, gestational age, and male:female ratio of referred babies

\begin{tabular}{|c|c|c|c|}
\hline & $\begin{array}{l}\text { Mean }(S D) \\
\text { birth weight (g) } \\
\text { (range) }\end{array}$ & $\begin{array}{l}\text { Mean (SD) } \\
\text { gestational age } \\
\text { (weeks) (range) }\end{array}$ & $\begin{array}{l}\text { Sex ratio } \\
\text { (male:female) }\end{array}$ \\
\hline $\begin{array}{l}\text { Accepted and transferred to St Mary's Hospital } \\
(n=263)\end{array}$ & $\begin{array}{l}1620(830)^{*}(580-4440) \\
\text { Median }=1380\end{array}$ & $\begin{array}{l}30 \cdot 8(4 \cdot 1) \dagger(23-42) \\
\text { Median }=30\end{array}$ & $158: 105(60 \%: 40 \%)$ \\
\hline $\begin{array}{l}\text { Declined but transferred elsewhere } \\
(\mathrm{n}=132)\end{array}$ & $\begin{array}{l}1520(700)(540-4000) \\
\text { Median }=1400\end{array}$ & $\begin{array}{l}30 \cdot 3(3 \cdot 8) \quad(24-40) \\
\text { Median }=30\end{array}$ & $78: 54 \quad(59 \%: 41 \%)$ \\
\hline $\begin{array}{l}\text { Declined and stayed at local hospital } \\
(\mathrm{n}=35)\end{array}$ & $\begin{array}{l}1330(620)^{*}(460-3000) \\
\text { Median }=1100\end{array}$ & $\begin{array}{l}29 \cdot 3(3 \cdot 5) \dagger(25-39) \\
\text { Median }=29\end{array}$ & $21: 14 \quad(60 \%: 40 \%)$ \\
\hline Total requests & $\begin{array}{l}1567(790)(460-4440) \\
\text { Median }=1380\end{array}$ & $\begin{array}{l}30 \cdot 5(4 \cdot 1) \quad(23-42) \\
\text { Median }=30\end{array}$ & $266: 177(60 \%: 40 \%)$ \\
\hline
\end{tabular}

${ }^{*} \mathrm{p}<0 \cdot 02 ; \mathrm{tp}<0 \cdot 025$.

(including those who died before transfer could be effected) was similar in those for whom request for transfer was accepted and those who were declined $(70 \% v 66 \%)$. The survival rate of babies who remained at their hospital of birth $(49 \%)$ was significantly lower than those who were transferred to the Regional Centre (71\%) and those who were transferred elsewhere $(73 \%)(\mathrm{p}<0 \cdot 025)$.

Among babies with respiratory failure the incidence of the various types of presentation was similar in those who remained in their hospital of birth and those who were transferred to the regional centre. Those remaining in their local hospital, however, had a lower mean birth weight (table 5). The survival rate of those with respiratory failure who remained in their hospital of birth $(47 \%)$ was significantly lower than those who were transferred to the regional centre $(72 \%)(p<0 \cdot 01)$. Babies with respiratory failure and birth weights of below $1500 \mathrm{~g}$ who were transferred to the regional centre or remained in their hospital of birth were also compared. The survival rate for those transferred (141) was $64 \%$ and for those remaining locally (22) was $36 \% \quad(p<0.05)$. There were no significant 
Table 5 Comparison between those babies with respiratory failure who were transferred to the regional centre and those who remained in their hospital of birth

\begin{tabular}{|c|c|c|c|c|}
\hline & & $\begin{array}{l}\text { No }(\%) \text { of babies } \\
\text { transferred } \\
(n=246)\end{array}$ & \multicolumn{2}{|c|}{$\begin{array}{l}\text { No }(\%) \text { of babies who } \\
\text { stayed locally } \\
(n=32)\end{array}$} \\
\hline \multicolumn{5}{|l|}{ Reason for referral: } \\
\hline Deteriorating respiratory distress & \multicolumn{2}{|c|}{$128 \quad(52 \cdot 1)$} & \multicolumn{2}{|l|}{$17 \quad(53 \cdot 1)$} \\
\hline Respiratory distress and apnoea & \multicolumn{2}{|c|}{$34 \quad(13 \cdot 8)$} & \multicolumn{2}{|l|}{$4(12 \cdot 5)$} \\
\hline Apnoea alone & \multirow{2}{*}{\multicolumn{2}{|c|}{$\begin{array}{ll}17 & (6 \cdot 9) \\
63 & (25 \cdot 6)\end{array}$}} & \multicolumn{2}{|l|}{$1 \quad(3 \cdot 1)$} \\
\hline Ventilatory failure from birth & & & \multirow{2}{*}{\multicolumn{2}{|c|}{$\begin{array}{r}10 \\
0\end{array}$}} \\
\hline Prolonged ventilator dependence & \multicolumn{2}{|c|}{$4 \quad(1.6)$} & & \\
\hline Mean (SD) birth weight (g) & \multicolumn{2}{|c|}{$1610 \quad(800)$} & \multicolumn{2}{|l|}{$1330(620)^{*}$} \\
\hline Mean (SD) gestational age (weeks) & \multicolumn{2}{|c|}{$30 \cdot 5(4 \cdot 0)$} & \multicolumn{2}{|l|}{$29 \cdot 3(3 \cdot 5)$} \\
\hline Sex ratio (male:female) & \multicolumn{2}{|c|}{$148: 98$} & \multicolumn{2}{|l|}{$19: 13$} \\
\hline Survived & \multicolumn{2}{|c|}{$177 \quad(72 \cdot 0)$} & \multicolumn{2}{|l|}{$15(46 \cdot 9) \dagger$} \\
\hline \multicolumn{5}{|l|}{${ }^{*} \mathrm{p}<0.05 ; \dagger \mathrm{p}<0.01$} \\
\hline \multicolumn{5}{|c|}{ Table 6 Outcome of requests to transfer multiple births } \\
\hline & $\begin{array}{l}\text { Babies accepted a } \\
\text { regional centre } \\
(n=14)\end{array}$ & $\begin{array}{l}\text { Babies accepted } \\
\text { elsewhere } \\
(n=27)\end{array}$ & $\begin{array}{l}\text { Babies who } \\
\text { remained locally } \\
(n=7)\end{array}$ & $\begin{array}{l}\text { Total } \\
(n=48)\end{array}$ \\
\hline Mean (SD) birth weight (g) & $1490(610)$ & $1420(570)$ & $1060(400)$ & $1390(570)$ \\
\hline Mean (SD) gestation age (weeks) & $30 \cdot 0(2 \cdot 1)$ & $30 \cdot 2(3 \cdot 1)$ & $27 \cdot 1(2 \cdot 0)$ & $29.7(2 \cdot 8)$ \\
\hline Sex ratio (male:female) & $7: 7$ & $15: 12$ & $6: 1$ & $28: 20$ \\
\hline No $(\%)$ survived & $12(85 \cdot 7)$ & $16(59 \cdot 3)$ & $3(42 \cdot 9)$ & $31(64 \cdot 6)$ \\
\hline
\end{tabular}

differences in birth weights, gestational ages, or gender between these two groups.

Babies who were the products of multiple pregnancies accounted for $48(11 \%)$ of the requests for transfer (table 6). Only $14(29 \%)$ were accepted for transfer to the regional centre. These 14 babies had a lower birth weight but similar gestational age compared with other accepted babies. Their survival rates was $86 \%$. Five sets of twins were accepted and four single babies when a request was made to take only one of a pair. Eight sets of twins were declined and of these, four pairs were later split and accepted elsewhere. Thirteen single twins, one of a set of triplets, and all four of a set of quadruplets were also declined admission. Babies of multiple pregnancies who were not admitted to any intensive care unit were smaller and significantly less mature than those accepted. They had the lowest survival of any group considered here $(43 \%)$.

\section{Discussion}

Many factors, not considered in this study, influence the work load of a regional referral centre and thereby determine the extent to which requests for transfer can be accommodated. For example, during the period of this study the number of babies admitted to the neonatal medical unit after in utero transfer rose from 32 in 1983 to 69 in 1985. Babies with birth weights of $1000 \mathrm{~g}$ or less demand a disproportionate amount of resources. In 1983, 43 such babies were cared for on the unit, rising to 68 in 1985. In addition, the North Western Regional Health Authority has predicted a rise in the region's total births from 53100 in 1981, to 56000 in 1986, and 62000 in 1993.

Whereas we reported in an earlier study that 42 babies in a 12 month period were declined admission and had to remain at their hospital of birth, the current study showed that only 35 babies in three years had to remain locally. ${ }^{1}$ The mortality of those babies who remained at their hospital of birth, however, was still significantly higher compared with those transferred suggesting that unnecessary deaths are still occurring. The new neonatal referral service based at Hope Hospital, Salford accepted between 50 and 65 neonatal referrals annually during this study, many being primary referrals to that unit. Yet despite this, and despite and increase in size of the existing referral centre at this hospital, 25 babies that we know of had to be transferred to other health regions for intensive care at great incovenience to parents. The circumstances that make it necessary for a neonatal intensive care unit 
to decline further admissions often persist for several days. District hospital paediatricians are aware of this and might make direct extra regional referrals without trying to contact their own regional centre. We suspect that some district paediatricians, despairing of previous unsuccessful attempts to secure the admission of babies to their regional centre, cease to request referral of babies requiring intensive care, and instead do the best they can locally. Our current system of documentation does not register such cases.

It was not the purpose of this paper to compare in detail the quality of neonatal care according to whether babies were accepted or declined at the regional centre. The data do not allow that. It cannot go unnoticed, however, that the mortality of ill babies who were unable to be accommodated at the regional centre or elsewhere was significantly higher than those babies who were transferred. Those babies who remained at their hospital of birth had a similar pattern of illness to those who were transferred, but they were rather smaller and more immature. When intensive care is offered to an extremely preterm baby resources are committed to one patient for many weeks or months, whereas those resources might be used in the same period of time by several more mature babies each needing only a week or two of intensive support. It is possible that the bias towards smaller and more immature babies among those who remained in their hospital of birth might be due to selection in so far as when space is limited in the regional centre more mature infants may get preference. If a request for transfer of an extremely small preterm infant is declined the referring paediatrician may not continue to try other referral centres.

Requests for the transfer of babies of multiple pregnancy generate special problems. Practical difficulties arise in the actual transfer of two or more babies and it may only be possible to accept one baby for transfer and care. Which baby should it be? The remaining babies may be offered no support, or transferred to another unit miles away creating major problems with respect to parental visiting. These important considerations remain unresolved.

Indications for transfer and the reason for refusal remain broadly the same as in our earlier report. ${ }^{1}$ Accepting a neonatal transfer commits the unit to caring for the baby for as long as is necessary and this may be for weeks or months. Excellent standards of care must be offered to all babies accepted and we do not accept the 'pack in as many as you can' philosophy. Indeed, at times it may be necessary to shut cots in order to maintain standards with resource shortages. Adequate numbers of skilled nurses are mandatory for the safe running of a neonatal unit. We found in this study as before that a shortage of nurses was often a part reason, and sometimes the sole reason for declining a transfer request. ${ }^{1}$ We suspect that at times skilled nursing staff may be subjected to extreme emotional pressures regarding neonatal transfer requests. When the unit is working to capacity, if they suspect that a baby will die unless transferred they might agree to take on more work than is desirable for the safety of the unit.

We thank Dr M Robinson and Dr G Hambleton for the data regarding Hope Hospital, Salford.

\section{References \\ ' Sims DG, Wynn J, Chiswick ML. Outcome for newborn babies declined admission to a regional neonatal intensive care unit. Arch Dis Child 1982;57:334-7. \\ 2 Jivani SKM. Evaluation of neonatal intensive care in a district general hospital. Arch Dis Child 1986;61:148-52.}

Correspondence to Dr DG Sims, North Western Regional Perinatal Centre, St Mary's Hospital, Whitworth Park, Manchester M13 $0 \mathrm{JH}$.

Accepted 18 October 1987 